International Journal of Multidisciplinary Research AND ANALysis

ISSN(print): 2643-9840, ISSN(online): 2643-9875

Volume 03 Issue 12 December 2020

DOI: 10.47191/ijmra/v3-i12-10, Impact Factor: 5.522

Page No.- 324-333

\title{
Monitoring and Evaluation as a Tool of Ensuring Efficiency of Increasing the Qualification of Pedagogical Staff
}

\author{
Klara Irismatovna Akhmetova ${ }^{1}$ \& Odinaxon Rasulovna Jamoldinova ${ }^{2}$ \\ ${ }^{1}$ Senior lecturer, Uzbek State University of World Languages, Tashkent, Uzbekistan \\ ${ }^{2}$ Professor, Uzbek State University of World Languages, Tashkent, Uzbekistan
}

\begin{abstract}
This article is devoted to monitoring the continuing education system. In it, monitoring is consideredas a tool, a means of ensuring the effectiveness of the process of continuing education of teaching staff, conceptual aspects of developing monitoring of the effectiveness of the process of continuing education of teaching staff, the characteristic features of evaluating the effectiveness of the process of improving the qualifications of teaching staff.

Keywords: monitoring, educational monitoring, pedagogical monitoring, conceptual aspects, the system of advanced training, the process of advanced training, the effectiveness of advanced training, assessment.
\end{abstract}

\section{Introduction}

Since gaining sovereignty and independence, Uzbekistan has chosen its own path of development, building a democratic rule of law and an open civil society, and forming a socially oriented market economy. Reforms in the material and spiritual spheres of society are carried out taking into account the mentality of the people, their national traditions, rich historical and spiritual heritage, as well as the positive experience of developed countries.

Education is defined as one of the most important priorities of social development in Uzbekistan. Conceptual foundations for reforming the education system, as well as training and retraining of personnel were developed on the initiative and with the direct participation of the first President of our country I.A. Karimov. The core of this concept is a fundamentally new, unparalleled national model of personnel training. Its essence and distinctive feature is systemic integrity, which includes personality, state and society, continuous education, science and production as its main components [2. P. 5].

As the first President of the Republic of Uzbekistan IA Karimov stated: "At every stage of the formation of market relations, an obstacle at every step was the lack of qualified personnel and specialists, therefore the most important task is to increase the level of education in our republic. What tasks we would not set today, what problems would not have to be solved, in the end everything rests on personnel. Without solving this important issue, the formation of a prosperous, strong democratic state and civil society is impossible. The new educational system should stimulate the training of highly qualified personnel who will adequately represent Uzbekistan in the world community. "

The future of any society is determined by the degree to which its education system is developed, which is its integral part and vital necessity.

\section{Methodology}

This is qualitative research using the content analysis approach. About twenty two works and other materials are used to Monitoring and Evaluation as a Tool of Ensuring Efficiency of Increasing the Qualification of Pedagogical Staff. Besides that, the researcher had used journals, manuscripts and articles to collect data related to the research.

\section{Results and Discussion}

Today, in the conditions of independence of our country, the reform and improvement of its continuous education system, the rise to a new quality level, the introduction of advanced pedagogical and information technologies, as well as increasing the efficiency of education have been elevated to the rank of state policy. 


\section{Monitoring and Evaluation as a Tool of Ensuring Efficiency of Increasing the Qualification of Pedagogical Staff}

"One of the main tasks of our state is the upbringing of a spiritually rich person, the preparation of a new generation in moral and spiritual terms on the basis of the ideas of national revival" - noted the first President of the country I.A. Karimov.

An important role in the implementation of the above tasks is assigned to teachers. After all, it is the teacher who stands at the origins of the educational process, where a harmoniously developed generation is brought up. The solution of all problems and tasks is impossible without his participation, because no reform (and not only in education) can lead to success without the help of teachers and their active participation in the implementation of transformations.

The transformations taking place in all spheres of our society, innovative processes in economic and social life and, most importantly, the choice as the main task of reorganizing society - the task of emancipating the individual, creating conditions for each person for the free manifestation and development of their abilities, generate a situation in education when new requirements for the training and professional development of a teacher of a professional educational institution are updated. An urgent issue today is the improvement of the educational and professional level of the teachers themselves, the solution of which cannot be postponed. Since only an independent and creative professional, an active subject in the educational services market, having an individual style of professional activity, able to manage his intellectual potential, constantly developing his pedagogical competence, is capable of implementing modern ideas.

In order to radically improve the vocational education system, radically revise the content of personnel training in accordance with the priority tasks of the socio-economic development of the country, provide the necessary conditions for training specialists with higher education at the level of international standards, the President of the Republic of Uzbekistan adopted a number of resolutions, where the tasks aimed on the further development of this system. In particular, these are such decrees as the Resolution of the President of the Republic of Uzbekistan Sh.Mirziyoyev PP-2909 "Omers for the further development of the higher education system" dated April 24, 2017, Resolution of the President of the Republic of Uzbekistan Sh.Mirziyoyev PP-3151 "On measures to further expand participation sectors and spheres of the economy in improving the quality of training of specialists with higher education "dated July 27, 2017, Resolution of the President of the Republic of Uzbekistan Sh.Mirziyoyev PP-3775" On additional measures to improve the quality of education in higher educational institutions and ensure their active participation in ongoing large-scale reforms "of June 5, 2018, Decree of the President of the Republic of Uzbekistan Sh.Mirziyoyev UP-5544" On approval of the strategy of innovative development of the Republic of Uzbekistan for 2019 - 2021 "dated September 21, 2018, Decree of the President of the Republic of Uzbekistan Sh.Mirziyoyev UP-5763" On measures to reform management in the spheres of higher and secondary social education "from July 11, 2019 and others.

In accordance with the changes taking place in society and in the system of personnel training, new requirements are imposed on the existing system of advanced training for teaching staff:

- A consumer - a teacher who uses her services and wants these services to meet his needs;

- Customers - a society that has taken a benchmark to create conditions for the development of the personality of each of its members and, accordingly, the personality of the teacher himself and the state, which imposes requirements on the level of education of teaching staff in the form of state requirements;

- A manufacturer of educational services - the education system itself, which also requires the teaching staff to "outstrip" the level of their own development.

However, the existing system of advanced training of teaching staff contains a number of fundamental contradictions, which are reflected in the National Program for the Training of Personnel of Uzbekistan:

- Between the requirements for the qualifications of teachers in the vocational education system that have increased in the new socio-economic conditions and the level of their ability and professional preparedness to work in market conditions.

- Between the objective need to reform the system of advanced training of teaching staff and the ability to effectively manage this process at the level of the individual, team, educational institution that carries out advanced training a2. P. 32].

Based on the identified contradictions, the research problem is determined: what are the possibilities of monitoring and evaluation in ensuring the effectiveness of professional development of teaching staff in the system of continuous education.

As is known, the domestic education system has undergone a number of qualitative changes in its development. One of the central problems in the field of education has become the implementation of the idea of lifelong education - a priority area that ensures the socio-economic development of the Republic of Uzbekistan, satisfying the economic, social, scientific and technical needs of the individual, society, and the state.

The idea of lifelong education originated in the 20th century, but its origins can be found even in the days of ancient philosophers. The universal and philosophical significance of this idea is great, since its meaning is to provide each person with the opportunity for continuous improvement, creative and professional development, renewal of knowledge, skills, skills and qualities throughout life, and therefore contribute to the prosperity of the entire society. 


\section{Monitoring and Evaluation as a Tool of Ensuring Efficiency of Increasing the Qualification of Pedagogical Staff}

It is believed that the term "continuing education" was first used in 1968 in the materials of the General Conference of UNESCO. After the publication of the report of the commission under the leadership of E. Fora (1972), UNESCO adopted a decision that recognized lifelong education as the main principle, the "guiding structure" for innovations or reforms in education in all countries of the world. Since the mid-1970s. The idea of lifelong education finds support in almost all countries, becoming the dominant vector of educational reforms.

Continuous education, as a pedagogical system, is an integral set of means, methods and forms of acquiring, deepening and expanding general education; professional competence; culture; education of civil and moral maturity; aesthetic and ecological attitude to reality.

The development of the advanced training system is based on:

(1) On the priority of education, which is determined by the priority of the nature of its development, the prestige of knowledge, education and high intelligence;

(2) On the democratization of education, which is determined by its accessibility, the variety of forms of presentation to a person at any age of the conditions for obtaining and deepening knowledge in accordance with their own interests, needs and opportunities. Democracy is ensured by the freedom of transition from one educational institution to another, from a lower level of education to a higher one, to the accelerated inclusion in labor activity of both those who cannot cope with the requirements of the curriculum during a given period of development, and those who show the ability to master more quickly. material. Democracy means equality of opportunities for citizens, representatives of all strata of the population and social groups, healthy and disabled people, taking into account national and regional characteristics and interests;

(3) On the humanization of education, which is determined by its appeal to a person. Humanization manifests itself in preparing a person for real life, in organizing his active life at all stages of learning, in creating conditions for the development of those abilities that are inherent in a given personality and which would allow each person to realize them at the highest possible level in life by overcoming the authoritarian-technocratic an approach in which a person was viewed as a programmable element of the educational system that does not have freedom of choice, real possibilities of goal-setting and goal-fulfillment. The formation of an attitude towards a person as a goal, and not a means of social progress, helps to overcome all types of alienation, neglect of differences in the psychophysiological capabilities of people;

(4) On the humanization of education, which is determined by the formation of an aesthetically rich worldview, high spirituality, culture and creative thinking in students;

(5) On the national orientation of education, which lies in its organic unity with national history, folk traditions and customs, preservation and enrichment of the culture of the peoples of Uzbekistan, recognition of education as the most important instrument of national development, respect for the history and culture of other peoples.

Based on the above, we can assert that the system of professional development is:

- For society as a whole - a mechanism for the expanded reproduction of its cultural and professional potential, a condition for the development of social production, acceleration of the country's socio-economic progress;

- For the state - the leading area of social policy to ensure favorable conditions for the general and professional development of the personality of each person.

Professional development, i.e. the education of personnel in the postgraduate period is called differently: subsequent, secondary, additional, post-basic, etc. (Vladislavlev A.P., Abbasova O.S., Onushkin V.G., Ogarev E.I., Zagorskiy A.P., Kuznetsova T.A., Aminov A.Kh. and others).

We, in accordance with the Law of the Republic of Uzbekistan "On Education", will adhere to the definition of the concept of advanced training as a component of the system of continuing education [1. P. 34].

The main task of the advanced training system, defined by the Law of the Republic of Uzbekistan "On Education", "is to continuously improve the qualifications of teaching staff and heads of educational institutions." [1. pp. 124-125].

According to the Law of the Republic of Uzbekistan "On Education", advanced training "is part of the system of continuing education and is a set of relevant educational programs, a network of educational institutions implementing them and management structures" [P.129].

The Law of the Republic of Uzbekistan "On Education" emphasizes: "Professional development of personnel is carried out in order to deepen and update professional knowledge, skills and abilities, in accordance with the requirements of social development, scientific and technological progress, taking into account the individual needs of people" [1. pp. 120].

Also, special attention is paid to the system of advanced training in the National Program for Personnel Training of the Republic of Uzbekistan. The Program notes that for the organization and development of the system of advanced training of personnel it is necessary:

- To form the structure and content of the activity of the personnel development and management system; 


\section{Monitoring and Evaluation as a Tool of Ensuring Efficiency of Increasing the Qualification of Pedagogical Staff}

- To provide training and staffing with highly qualified staff of teachers;

- create a regulatory framework for the system of advanced training of personnel, ensuring the formation of a competitive environment in this area and its effective activity;

- Develop and introduce into practice a system of state certification and accreditation of educational institutions for advanced training of personnel;

- To promote the creation and development of state and non-state educational institutions, providing prompt and effective professional development of personnel in accordance with the needs of the state and non-state sectors of the economy, organizations and institutions of various forms;

- To develop, create and master in practice advanced technologies and equipment for professional training, as well as simulators of complex science-intensive technological processes [2. pp. 126-127].

In the Resolution of the President of the Republic of Uzbekistan Sh.Mirziyoyev PP-4732 "On measures to further improve the system of retraining and advanced training of teaching staff of higher educational institutions" dated June 12, 2015, it is noted that advanced training of teaching personnel is a systematic update of professional knowledge, skills and abilities on the taught discipline or course, pedagogical and information technologies, interactive teaching methods based on state requirements for the types of education, ensuring the constant growth of professional and pedagogical skills, conducting the educational process at a high scientific and methodological level. Also in the Resolution for faculties, centers, retraining and advanced training courses for teaching staff, the main tasks are determined, which are as follows:

- On the basis of individual assignments or targeted programs of the customer, in agreement with the ministries and departments, develop differentiated curricula and programs;

- Are responsible for organizing and conducting at the proper level retraining and advanced training of management and teaching staff;

- Introduction of interactive teaching methods, modern pedagogical and information technologies using the global Internet, aimed at stimulating critical and creative thinking, self-education of teachers [pp. 45-47].

In this regard, we will outline the basic requirements for advanced training in the system of continuing education. They are as follows:

- Predictability of the process of professional development - the fundamental orientation of this system (to a higher degree than it is expressed in other stable links of education) to dynamic changes in the socio-economic environment and variable educational needs of the population;

- Multivariance of professional development - the basis for ensuring the diversity of educational services in accordance with the educational needs of the individual;

- Adaptability of the professional development process - the ability to flexibly reorient the content, forms and methods of teaching, which creates great opportunities for the operational orientation of educational services to individual individual needs;

- The availability of the professional development process is the most important condition of the state guarantee at all stages of the life course.

Thus, the system of advanced training, as one of the components of lifelong education, is one of the significant factors in the development and purposeful transformation of society as a whole, its individual layers, structures, and complexes. In the context of the growing importance of the personal factor of advanced training, it should become an effective, demanded institution that forms a scientific worldview of a person and society, free from dogmas and stereotypes, an intellectual, cultural and moral-ethical social mentality based on the achievements of civilization, on the best national and local traditions, on democratic principles of respect and protection of the rights of citizens, of all strata and groups.

At the same time, despite the fact that in recent years many steps and measures have been taken to improve the system of advanced training, the potential and quality of the educational process in this system does not fully meet modern requirements.

In order to raise the system of advanced training of management and pedagogical personnel to a new level, the widespread introduction into practice of modern forms of improving their professional skills, as well as a differentiated and alternative continuous system of advanced training, taking into account the results of scientific and scientific-pedagogical activities in the Decree of the President of the Republic of Uzbekistan Sh.Mirziyoyev UP-5789 "On the implementation of a system of continuous professional development of management and teaching staff of higher educational institutions" dated August 27, 2019, the following tasks were identified:

- Introduction of mechanisms for continuous updating of professional knowledge, skills and mastery of management and teaching staff, improving their professional training at the required level in accordance with modern requirements to ensure the quality of higher education; 


\section{Monitoring and Evaluation as a Tool of Ensuring Efficiency of Increasing the Qualification of Pedagogical Staff}

- Ensuring the introduction into practice and monitoring of direct and indirect forms of professional development based on the principles of variability and complementarity;

- Creation, based on the scientific and pedagogical potential of management and teaching staff, opportunities for independent choice and development of forms of continuous professional development, focused on meeting their professional needs;

- Development of the skills of management and teaching staff in the field of scientific and practical research, technological development, innovations in the disciplines taught, as well as modern methods of organizing the educational process on the basis of continuous improvement of their professional skills;

- Regular updating of qualification requirements, curricula and programs for advanced training of management and teaching staff with the widespread introduction of modern highly effective educational and innovative technologies, advanced foreign experience, organization and ensuring the effectiveness of their activities at the proper level;

- Development of leadership and teaching staff skills in mastery of advanced pedagogical, information-communication and innovative technologies and their active implementation in the educational process using the worldwide information network Internet, multimedia systems and distance learning methods;

- Increasing the level of practical mastering of foreign languages by leading and pedagogical personnel, creating opportunities for the continuous growth of professional skills, the effectiveness of their pedagogical and scientific activities.

An important role in the implementation of the above tasks is assigned to the monitoring and evaluation of the advanced training system.

The study found that in the mid-80s. XX century. formed the need to provide society with more extensive and reliable information about learning outcomes, about the quality and effective aspects of educational systems, their financing, management, etc., which arose as a result of the rapid development of education in industrialized countries in the postwar period. Some foreign experts believe that interest in this issue was partly stimulated by the published in 1983 in the USA and now widely known report "A Nation in Danger", which showed the unsatisfactory state of the American school and was based, among other things, on specially conducted studies of education in other countries. [5. P. 56].

According to N. Botany, at the end of the 80 s. the changed conditions of socio-political and economic development have led to the emergence of factors that together again aroused great interest in expanding and enriching the comparative information provided to society on the state of education systems:

- Persistence of inconsistencies and inequalities within and between education systems;

- Changed expectations for feedback and performance;

- The development of public services and assessment mechanisms that are more sensitive to quality aspects of performance than simple statistics;

- Search for measures to improve the quality and increase the effectiveness of education. [7. P.88].

And since "it is information about a more general system that structures and controls the development of more private systems, ... opposing chaos, controls the forces of order and creation," the characteristics and direction of development of a particular educational system largely depends on the functions that information performs in it. [11. P.187].

The functions of information are presented most fully in works that consider the problems of communication between subjects of educational activity. A.A. Bodalev identifies the following functions in the system of human interactions with other people: information and communication, regulation and communication and affective and communicative. [13 pp.67-68]. These functions should be filled with pedagogical content. V.G. Gorb reasonably calls this information pedagogical and distinguishes its following functions:

- Socio-pedagogical - contributes to the pedagogical development of participants in the educational process, as well as the creation of optimal psychological conditions for the implementation of educational goals;

- Pragmatic - allows, on the basis of pedagogical information, to solve pragmatic tasks of a personal and socially significant nature at various levels of educational activity;

- Integrative - combines local sources of information in order to create a system that has a positive effect on the formation of the educational process in an educational institution;

- Diagnostic - allows the subjects of the educational process to determine the direction, nature and quality of their activities and, on this basis, to take constructive measures to more effectively achieve their goals;

- Socio-prognostic - outlines the prospects and conditions for the further development of the personality of the participants in the educational process;

- Socially-normative - provides a socially oriented and normatively conditioned nature of educational activities [10. pp.10-

11]. 


\section{Monitoring and Evaluation as a Tool of Ensuring Efficiency of Increasing the Qualification of Pedagogical Staff}

These approaches to the classification of pedagogical information, built on a functional basis, are the basis for developing the concept of aspects of pedagogical monitoring.

In the course of the research, on the basis of an extensive analysis of scientific sources, it was established that in the scientific and pedagogical literature there is no unity in the definition of the concept of "monitoring" and the boundaries of its application in the field of advanced training of teaching staff.

The content analysis of scientific research has highlighted various approaches to the definition of "monitoring", which reveal the methodological features of its application in the field of education and are designated as: "educational monitoring" (A.N. Maiorov); "Professiographic monitoring" (SN Silina); "Qualimetric monitoring" (N.A. Kulemin); "Pedagogical monitoring" (N.V. Abramovskikh, A.S.Belkin, V.D.Zhavoronkov, L.P. Kachalova); “Monitoring the quality of education” (VP Bespalko); "Monitoring the quality of vocational training" (OA Abdulina); "Monitoring of education" (SE Shishova, VA Kalnei, MM Potashnik, LV Golish and others), "monitoring of the quality of education" (T.Kh. Abdukhalikov).

The process of a continuous scientifically grounded diagnostic and prognostic process for the optimal choice of educational goals, objectives and means of their solution [5].

Specially organized, systematic monitoring of the state of objects, phenomena, processes in order to assess, control, forecast [7].

Scientifically grounded system of periodic collection, generalization and analysis of information and presentation of the obtained data for decision making [14].

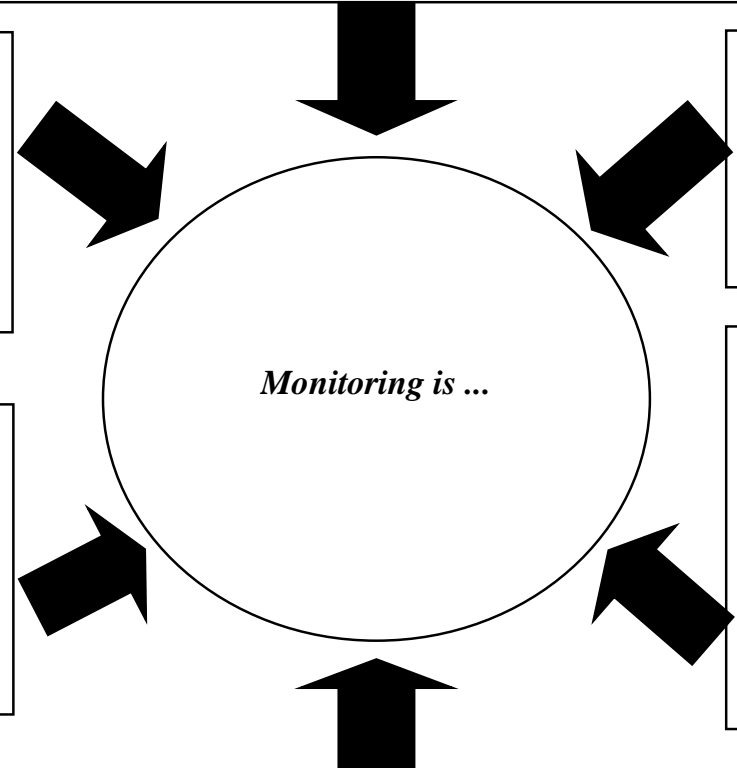

An independent management function, providing identification, assessment of the conducted pedagogical actions [9].

An independent management function that provides feedback, informing about the correspondence of the actual results of the activity of the pedagogical system to its ultimate goals [11].

Pedagogical monitoring implies long-term and systematic evidence-based tracking of research results and their comparison with a given standard [17].

Fig. 1. Variants of the definition of the concept of "monitoring" in pedagogy

Figure 1. it is clearly expressed how each definition reflects only one facet (side) of the multidimensional and integral phenomenon "monitoring". On the whole, it is a complex system (Fig. 2) designed to track the dynamics of the effectiveness of educational services and the state of pedagogical systems. It is a holistic management tool. Its internal structure, purpose, place and time of application are still to be determined.

"Monitoring" is (1) an independent management function that provides feedback, informing about the correspondence of the actual results of the activity of the pedagogical system to its ultimate goals [P. 32]; the most accurate definition of the concept of "monitoring", in our opinion, was given by T.A. Abdukhalikov, we will adhere to it in our study (2) the method of collecting data on the quality of student learning through testing and organization of other control works, where the norm with which the results are compared training, is the state educational standard a. C. 930.

Based on the above interpretations, in our understanding, "monitoring" is a multidimensional, integral and systemic concept.

Pedagogical monitoring implies long-term and systematic, scientifically grounded, specially organized observation and tracking of trends in the system and in the training facility itself in order to obtain information for comparing them with a given standard, their control, assessment, and forecast, as well as making management decisions.

The effectiveness of the professional development process is determined by the fact that its results must correspond to the goals of professional development and the end result set by regulatory documents 


\section{Monitoring and Evaluation as a Tool of Ensuring Efficiency of Increasing the Qualification of Pedagogical Staff}

Monitoring the effectiveness of the professional development process is a scientifically grounded method of continuous, control and evaluation, diagnostic and prognostic tracking of the progress of the professional development process and its development trends.

Monitoring the effectiveness of the professional development process performs the following functions:

- informational - regular, in accordance with the program and schedule of tracking the progress (results) of the professional development process on the basis of their constant fixation, assessment and in accordance with the specified criteria;

- Organizational - purposeful collection, generalization, systematization and analysis of information for making decisions on the optimal choice of educational goals and means of solving them or correcting the tasks performed, or predicting the development trends of the advanced training system;

- Control and evaluation - operational control and assessment of the effectiveness of the conducted pedagogical actions and the completeness of the implementation of the final goals of the system of advanced training of the teaching staff of the SSVE;

- Training - revealing the reasons for shortcomings in pedagogical work, outlining specific ways and means to ensure the effectiveness of the process of professional development; to teach teachers a deep understanding of the tasks they face, the ability to persistently and consistently implement them in practical activity, deeply analyze and self-critically evaluate its results;

- Developing - expanding the outlook of teachers, the growth of general culture, the development of intellectual, moral qualities.

- Correctional - operational search and clarification of the reasons for the current situation and, if necessary, amendment of the tasks performed;

- Diagnostic and prognostic - timely identification of changes occurring in the process of professional development, in particular in the system of advanced training of teachers of SSVE, in general, setting a pedagogical diagnosis, establishing causeand-effect relationships and promptly predicting their further development.

Successful achievement of the goal and solution of problems within an educational institution are possible only if the principles of organizing monitoring are implemented. Let's briefly consider their essence.

Purposefulness - lies in the precise choice of the monitoring goal, in order to direct all the work on monitoring the process of advanced training to address the main tasks facing the staff of the educational institution and to have an effective impact on its activities.

Comprehensiveness - involves the coverage of all aspects of teaching and educational work, all areas of the training process, all categories of teaching staff.

Objectivity is the definition of the real state of the advanced training system, the exact picture of pedagogical phenomena, their fundamental assessment.

Systematicity means a constant, systematic, logically consistent study of the state of the advanced training process, the work of teachers and students during the entire advanced training process (one month), which makes it possible to trace the growth of teachers' pedagogical skills, increase the effectiveness of the training process and knowledge of students.

Efficiency is its effectiveness, efficiency, timely adoption of managerial and pedagogical decisions during monitoring and following its results, prompt implementation of these decisions.

Effectiveness is achieved by a deep analysis of the identified shortcomings, objective conclusions, constructive suggestions, thoughtful follow-up work aimed at correcting the shortcomings.

Publicity is one of the important measures of public influence. The monitoring is carried out openly. The timing and objects of monitoring, as well as the goals of monitoring, are announced in advance. All its subjects participate in the discussion of the monitoring results: both inspectors, experts, students, and those teachers whose work is being analyzed.

One of the most pressing practical and scientific problems of improving the professional development process is the problem of its analysis and evaluation. The existence of the named problem is associated with the lack of adequate methodological means for solving the corresponding problems.

The process of improving the qualifications of a teacher is, first and foremost, the process of his progressive growth as a person and as a professional, a process that is carried out throughout his practical activity.

Based on the research carried out, we distinguish three stages (levels) of the teacher's professional development:

1. "Professional adaptation" (up to 5 years of teaching experience) - entering the profession, mastering a new social role, professional self-determination, the formation of social and professionally important qualities, experience of independent performance of professional activities, ie. at this level, a mechanical, reproductive (performing) transformation of oneself and one's professional experience takes place.

2. "Professionalization" (from 5 to 10 years of teaching experience) - the formation of a professional position, the integration of social and professionally important qualities and skills into relatively stable professionally significant constellations, 


\section{Monitoring and Evaluation as a Tool of Ensuring Efficiency of Increasing the Qualification of Pedagogical Staff}

the qualified performance of professional activities, i.e. at this level, there is an independent practical and mental transformation of oneself and one's professional experience at the level of tactical goals.

3. "Professional skill" (over 10 years) - full realization, self-realization of the personality in creative professional activity on the basis of movable integral pedagogical new formations, ie. at the third level, there is an independent real (practical) and ideal (mental) transformation of oneself and one's professional experience at the level of strategic goals.

We consider it advisable to take into account all three levels of professional development of a teacher when developing indicators and a criterion for assessing the qualifications of personnel.

Analysis of existing and own research in the field of theory and practice of professional development allows us to highlight the main parameters of the effectiveness of the professional development process, which can be recorded, measured and evaluated in the monitoring process with a greater degree of accuracy:

1. The concept of advanced training in an educational institution:

- Scientific ideas, approaches and attitudes;

- Goal-setting and means of achieving it.

2. Learning content:

- Relevance, novelty, availability;

- Compliance of the training content with state requirements

3. Professional and pedagogical competence of teachers:

- Orientation in the subject area;

- Possession of modern teaching technologies and pedagogical skills;

- The ability to integrate with the experience of world pedagogical science and domestic pedagogy to generalize and transfer their experience.

4. Infrastructure of an educational institution:

- Educational and material conditions for the implementation of modern teaching technologies: - educational, methodological and informational support of students.

5. Educational technologies for academic disciplines:

- Conceptual foundations, goal setting;

- Selection of training content and its structuring;

- The choice of teaching models in training sessions;

- Maintenance projects, their planning in the form of a technological map.

6. Professional competence and motivation of the listener in professional development.

Let us call the results that can be fixed with a lower (probabilistic) degree of accuracy:

7. The ability and readiness of the teacher to transfer - the application of the acquired knowledge, skills and abilities, as well as modern forms, methods and means of teaching in practice (in an educational institution), a creative approach, a desire to work on self-education, etc.

As the study showed, the issue of measuring and assessing the effectiveness of the educational process (within the framework of advanced training) based on its results is associated with the following parametric features:

(1) Can be assessed quantitatively in absolute values, in numbers, percentages, any other values (for example, in learning factors), but it is necessarily measured in mathematical parameters;

(2) Can be determined only qualimetrically, i.e. qualitatively descriptive or in the form of a point (rating) scale, or by expert assessments (experts assess the level of a particular quality, result: high, medium, low, minimal, sufficient, optimal, etc.);

(3) It is impossible to accurately measure and evaluate qualitatively and quantitatively, but nevertheless they can be predicted and probabilistically determined using methods for evaluating weakly formalized phenomena, processes based on the theory of fuzzy mathematics and nonparametric measurements of a pedagogical object.

Table 1. Indicators and criteria of qualimetrically measured results of the effectiveness of the professional development process, methods and means of their assessment

\begin{tabular}{|l|l|l|}
\hline № & $\begin{array}{l}\text { Indicators and criteria of the effectiveness of the educational } \\
\text { process (objects and qualimetric parameters of monitoring) }\end{array}$ & $\begin{array}{l}\text { Methods and means of assessment } \\
\text { (data collection toolkit) }\end{array}$ \\
\hline $\mathbf{0 1}$ & Continuing education concept & Expert review \\
\hline 1.1. & Scientific ideas, approaches and attitudes ("input") & Expert review \\
\hline 1.2. & Goal setting and means of achieving it &
\end{tabular}


Monitoring and Evaluation as a Tool of Ensuring Efficiency of Increasing the Qualification of Pedagogical Staff

\begin{tabular}{|c|c|c|}
\hline 02 & Learning content & \\
\hline 2.1. & Relevance, scientific availability & Expert review \\
\hline 2.2 & Goal setting & \\
\hline 2.3. & Compliance of training content with government requirements & Expert review \\
\hline 03 & \multicolumn{2}{|l|}{ Infrastructure of an educational institution } \\
\hline 3.1. & $\begin{array}{l}\text { Provision: the state of the educational and methodological complex } \\
\text { (at the beginning of the academic year) }\end{array}$ & $\begin{array}{l}\text { Expert review } \\
\text { Form } 2\end{array}$ \\
\hline 3.2. & $\begin{array}{l}\text { Provision of TSO and information technology (at the beginning of the } \\
\text { academic year) }\end{array}$ & $\begin{array}{l}\text { Expert review } \\
\text { Form } 2\end{array}$ \\
\hline 3.3. & $\begin{array}{l}\text { Information Resource Center (library fund) (at the beginning of the } \\
\text { academic year) }\end{array}$ & $\begin{array}{l}\text { Expert review } \\
\text { Form } 2\end{array}$ \\
\hline 04 & \multicolumn{2}{|l|}{ Control system } \\
\hline 4.1. & Tests, study assignments, exam questions & Expert review \\
\hline 4.2. & Administrative control and peer review schedule & Expert review \\
\hline 05. & \multicolumn{2}{|l|}{ Personnel potential } \\
\hline 5.1. & Staffing, their quality characteristics ("in progress", "exit") & Анализ; \\
\hline 5.2. & Professional and pedagogical competence ("in progress", "exit") & $\begin{array}{l}\text { Expert review; } \\
\text { Form } 1 \\
\text { Form } 6\end{array}$ \\
\hline 5.3. & Innovative activity ("entrance", "in the process", "exit") & $\begin{array}{l}\text { Expert review } \\
\text { Form } 1\end{array}$ \\
\hline 5.4. & $\begin{array}{l}\text { Ability to integrate with the experience of world pedagogical science } \\
\text { and domestic pedagogy, to generalize, transfer your experience }\end{array}$ & $\begin{array}{l}\text { Expert review } \\
\text { Form } 1\end{array}$ \\
\hline 06. & \multicolumn{2}{|c|}{ Professional competence and motivation of the listener in professional development } \\
\hline 6.1 & $\begin{array}{l}\text { The degree of sufficiency of general educational knowledge, skills and } \\
\text { abilities ("input" - "output") }\end{array}$ & Testing: tests, study assignments \\
\hline 6.2. & $\begin{array}{l}\text { The degree of sufficiency of psychological and pedagogical } \\
\text { knowledge, skills and abilities ("input" - "output") }\end{array}$ & Testing: tests, study assignments \\
\hline 6.3. & Willingness to transfer the received ZUN in practice ("exit") & $\begin{array}{l}\text { Self-assessment; questioning } \\
\text { Form } 4\end{array}$ \\
\hline 6.4. & $\begin{array}{l}\text { The level of motivation and needs of students to improve their } \\
\text { qualifications ("entry" - "exit") }\end{array}$ & $\begin{array}{l}\text { Self-assessment; questioning } \\
\text { Form } 4\end{array}$ \\
\hline 07. & \multicolumn{2}{|l|}{ Learning technology } \\
\hline 7.1. & $\begin{array}{l}\text { Conceptual foundations, goal setting, methods and means of } \\
\text { teaching, information, communication and management ("in the } \\
\text { process", "exit") }\end{array}$ & $\begin{array}{l}\text { Analysis; questioning } \\
\text { Form } 3\end{array}$ \\
\hline 7.2 . & Choice of learning models in classrooms & $\begin{array}{l}\text { Expert review } \\
\text { Form } 5\end{array}$ \\
\hline 7.3. & $\begin{array}{l}\text { Maintenance projects, their planning in the form of a technological } \\
\text { map }\end{array}$ & $\begin{array}{l}\text { Expert review } \\
\text { Form } 5\end{array}$ \\
\hline 08. & \multicolumn{2}{|l|}{ Real achievements of listeners } \\
\hline 8.1. & Actual results of current and interim control & $\begin{array}{l}\text { Testing: tests, study assignments; Form } \\
8 \text {, Form } 9\end{array}$ \\
\hline
\end{tabular}

4. Conclusion The conducted research allows us to formulate the following conclusions:

1. The process of advanced training is recognized as effective if its results (1) correspond to the specified regulatory documents, the goals of advanced training of SSVE personnel, (2) the needs of students and (3) are predicted in terms of the potential development of a professional, a specific person.

2. Within the framework of monitoring, the effectiveness of the professional development process is assessed. The subsequent analysis of the results makes it possible to determine the degree of compliance of the actual results of the activities of the educational institution, trainers and students with the set or projected goals of education. 


\section{Monitoring and Evaluation as a Tool of Ensuring Efficiency of Increasing the Qualification of Pedagogical Staff}

3. Monitoring is an independent function of managing the educational process, since the results of monitoring measurements can become the basis for making specific management decisions. At the same time, monitoring is organically interconnected with all functions and stages of the professional development process.

4. Monitoring affects goals, information, forecasts, decisions, organization and practical implementation of pedagogical activities, correction of processes and learning outcomes. One of the main, necessary conditions and grounds for monitoring are both state requirements and the normative model of a teacher in a specific area of professional development, since it is they that are the standard with which the real results of the professional development process of SSVE personnel are compared. Comparison of actual results with government requirements and the regulatory model is a component and benchmark for monitoring, followed by meaningful assessment and correction. Together, this constitutes the content of monitoring the entire process of professional development of teaching staff.

The foregoing allows us to state that pedagogical monitoring and assessment in the educational space allows obtaining information that has a constructive impact on the nature and effectiveness of the educational process, provides monitoring and assessment of the state of the entire advanced training system as a whole and the effectiveness of the learning process in particular, as well as identifying existing trends and forecasting further adequate actions to improve both the system and the process of professional development of the teaching staff of SSVE as a whole.

\section{References}

1) Law of the Republic of Uzbekistan "On Education" / Normative-legislative base of SSVE: overview and proposals for its development. -T .: IRSSPO, 1999. -S.

2) The Law of the Republic of Uzbekistan "On the National Program for Personnel Training" / Normative-legislative base of SSVE: review and proposals for its development. -T .: IRSSPO, 1999. -S.5-35.

3) Karimov I.A. "High spirituality is an invincible force." T .; Shark, 2008.

4) Decree of the President of the Republic of Uzbekistan Sh.Mirziyoyev UP-5789 "On the introduction of a system of continuous professional development of management and teaching staff of higher educational institutions" dated August 27, 2019.

5) Abdulina O.A. Monitoring the quality of vocational training / Higher education in Russia. 1998. No. 3. -FROM. 48.

6) Adizov B.R. Organizational and pedagogical conditions for improving the system of advanced training. Dis. channel of pedagogical sciences. -T: 1990. -S.22-36.

7) Alferov Yu.S. Monitoring the development of education in the world. // Pedagogy №7 2002. P.88[2].

8) Askerov Sh. Assessment of knowledge: search for a rational option. // J. Public education. \# 1. 2004.-p. 141.

9) Belkin A.S., Zhavoronkov V.D. Pedagogical monitoring of the educational process. Ekaterinburg, 2997, p. 10-15.

10) . Belkin A.S., Silina S.N. Professiographic monitoring of specialist training in the system of higher pedagogical education. Issue 4. Shadrinsk, 1999. -S.86-92.

11) Gorb V.G. Pedagogy No. 5 2003. P.10-11.

12) Gorb V.G. Pedagogical monitoring of the educational process in higher educational institutions of the system of the Ministry of Internal Affairs of Russia. Monograph. // Ur. Law Institute of the Ministry of Internal Affairs of Russia, Yekaterinburg, 1998, p. 25.

13) Egorov V.S. Rationalism and synergetism. M: 1997.S. 187.

14) Zhavoronkov V.D., Korotaeva E.A. Monitoring the educational process as a pedagogical problem. Ekayerinburg, 1999.

15) Informational message on the eighth session of the Oliy Majlis of the Republic of Uzbekistan. Pravda Vostoka dated April 5, 2002, p. 5.

16) Kodzhaspirova G.M., Kodzhaspirov A.Yu. Pedagogical Dictionary. M.; Academia, 2000.

17) Mayorov A.N. Monitoring the social efficiency and conditions of the educational systems. // School technologies, No. 5, 1999, pp. 84-115.

18) Orlov A.A. Monitoring of innovative processes in education. // Pedagogy, No. 3, 1996, pp. 10-12.

19) Silina S.N. Implementation of the technology of pedagogical monitoring in the process of preparing children for schooling. Shadrinsk, 2001

20) Social psychology. Edited by A.N. Sukhov, A.A. Derkach 2nd ed. M., 2002. P.67-68

21) Shishov S.E., Kalnei V.A. Monitoring the quality of education. Pedagogical Society of Russia. M.; 2000, pp. 38-40.

22) Formation of a knowledge-based society. New tasks of higher education. World Bank Report. M.: Ves mir, 2003; Continuing education and the need for it / Otv. ed. G. A. Klyucharev. Moscow: Nauka, 2005. 